\title{
Response to Radiation Therapy
}

\author{
BEATRIZ E. AMENDOLA, M.D. \\ RAYMOND HUTCHINSON, M.D. \\ H. BARTON GROSSMAN, M.D. \\ MARCO A. AMENDOLA, M.D.
}

From the Departments of Radiation Oncology, Pediatrics (Hematology Division), Surgery (Urology Section), and Radiology, University of Michigan, Ann Arbor, Michigan

\begin{abstract}
Between January, 1975, and December, 1984, at the University of Michigan Medical Center, 17 boys with leukemia presented with overt or occult isolated testicular relapse. Diagnosis was obtained by bilateral open-wedge biopsies of the testes. All the patients were treated with combined local testicular irradiation and systemic chemotherapy. In only 1 of the 17 patients (6\%) testicular leukemia developed as the only site of relapse. It appears that doses in the range of 2,000 to 2,400 cGy in 10 to 12 fractions achieve optimum control of leukemic infiltration of the testes.
\end{abstract}

Acute lymphoblastic leukemia (ALL) is the most common cancer and the second leading cause of death in children under fifteen years of age. ${ }^{1}$ About 85 per cent of the children who survive three to five years without having a bone marrow or extramedullary relapse will remain in prolonged remission and may be considered cured. $^{2}$

Isolated relapse in extramedullary sites often precedes bone marrow relapse. The median survival after isolated relapse is about ten months for bone marrow, eighteen months for testes, and twenty months for central nervous system (CNS), respectively. ${ }^{3}$ Isolated testicular relapse is replacing the CNS as the major site of extramedullary relapse. It has been reported in 14.8 per cent of boys under treatment ${ }^{4}$ and in as high as 41 per cent of boys in whom maintenance therapy was stopped after three or more years of continuous complete remission. ${ }^{5}$

Occult testicular leukemia was detected by elective bilateral open-wedge biopsies in 5 of 59 $(8.5 \%)$ boys in continuous complete remission for three years, as reported by Askin et al. ${ }^{6}$
Radiation is the preferred method of treatment for testicular relapse; however, the optimal dose to achieve maximum local control of leukemic testicular infiltrates with minimal tissue damage has not been individualized. Because new chemotherapeutic protocols are increasing the numbers of patients achieving remission, this information is of even greater relevance.

\section{Material and Methods}

From January, 1975, to December, 1984, 17 boys with the diagnosis of ALL received testicular irradiation for extramedullary relapse at the University of Michigan Hospital. Their ages ranged from ten months to seventeen years (average of 6.5 years) (Table I). Patients were treated with systemic chemotherapy as per Children's Cancer Study Group Protocols. They also received prophylactic cranial irradiation. Five of 17 patients had occult testicular leukemia, and 12 had overt testicular leukemia at the completion of three years of maintenance 
TABLE I. ALL/testicular leukemia

\begin{tabular}{|c|c|c|c|c|c|}
\hline Age (Yrs) & $\mathrm{Dx}(\mathrm{Y} \mathbf{r})$ & $\begin{array}{l}\text { Testicular } \\
\text { Relapse }\end{array}$ & $\begin{array}{c}\text { RT/Field } \\
\text { (Total cGy/Fx) }\end{array}$ & Machine & Status \\
\hline 4 & $1 / 77$ & $7 / 79$ & $2,000 / 250$ & $250 \mathrm{kV}$ & 5/85 NED \\
\hline \multirow[t]{2}{*}{3} & $7 / 79$ & $1 / 82$ & & & \\
\hline & & $1 / 84$ isolated & $2,400 / 200$ & $15 \mathrm{meV}$ & 5/85 NED \\
\hline 10 & $7 / 78$ & $\begin{array}{l}10 / 80 \text { occult } \\
10 / 82 \text { Bx fibrosis }\end{array}$ & $2,400 / 200$ & $12 \mathrm{meV}$ & 3/85 NED \\
\hline 3.5 & $7 / 74$ & $10 / 79$ occult & $2,000 / 180$ & $250 \mathrm{kV}$ & $\begin{array}{l}\text { 4/85 NED } \\
\text { gonadal failure }\end{array}$ \\
\hline 3 & $10 / 79$ & $\begin{array}{c}1 / 82 \\
\text { (2) }\end{array}$ & & & \\
\hline & & 12/84 fibrosis & $2,400 / 200$ & $12 \mathrm{meV}$ & $\begin{array}{l}\text { 5/85 NED } \\
5 / 85 \text { NFD }\end{array}$ \\
\hline 7 & $7 / 78$ & 2/81 occult & $2,400 / 200$ & $9 \mathrm{meV}$ & \\
\hline 11 & $11 / 78$ & $3 / 84$ occult & $2,400 / 200$ & $12 \mathrm{meV}$ & $10 / 84 \mathrm{BM}$ relapse \\
\hline 12 & $10 / 78$ & $5 / 79$ & $3,000 / 300$ & $250 \mathrm{kV}$ & $\begin{array}{l}\text { 6/79 DOD } \\
\text { testes neg. }\end{array}$ \\
\hline 2.5 & $6 / 76$ & $8 / 79$ & $2,000 / 200$ & $250 \mathrm{kV}$ & $\begin{array}{l}\text { 10/80 dead } \\
\text { CNS bleeding; } \\
\text { testes neg. }\end{array}$ \\
\hline 11 & $8 / 76$ & $9 / 78$ & $2,000 / 200$ & ${ }^{60} \mathrm{Co}$ & $\begin{array}{l}\text { 8/79 DOD } \\
\text { testes neg. }\end{array}$ \\
\hline $10 \mathrm{mos}$ & $12 / 76$ & $1 / 78$ & $2,180 / 180$ & ${ }^{60} \mathrm{Co}$ & $\begin{array}{l}\text { 8/78 DOD } \\
\text { testes neg. }\end{array}$ \\
\hline 2 & $5 / 77$ & $\begin{array}{c}11 / 77 \\
2 / 78 \text { fibrosis }\end{array}$ & $2,000 / 200$ & ${ }^{60} \mathrm{Co}$ & $\begin{array}{l}\text { 3/79 DOD } \\
\text { testes neg. }\end{array}$ \\
\hline 4 & $6 / 74$ & $11 / 77$ & $1,800 / 180$ & ${ }^{80} \mathrm{Co}$ & $\begin{array}{l}\text { 6/79 DOD } \\
\text { testes neg. }\end{array}$ \\
\hline 4.5 & $1 / 75$ & 10/78 occult & $2,000 / 200$ & $250 \mathrm{kV}$ & $\begin{array}{l}\text { 12/80 DOD } \\
\text { testes neg. }\end{array}$ \\
\hline 17 & $7 / 75$ & $10 / 77$ & $2,000 / 200$ & $250 \mathrm{kV}$ & $\begin{array}{l}\text { 11/79 DOD } \\
\text { testes neg. }\end{array}$ \\
\hline 8 & $2 / 81$ & $3 / 81$ & $2,400 / 12$ & $15 \mathrm{meV}$ & $\begin{array}{l}\text { 9/82 DOD } \\
\text { testes neg. }\end{array}$ \\
\hline 13 & $3 / 79$ & $11 / 79$ & $2,400 / 12$ & ${ }^{60} \mathrm{Co}$ & $\begin{array}{l}\text { 7/80 DOD } \\
\text { testes neg. }\end{array}$ \\
\hline
\end{tabular}

$\mathrm{KEY}: \overline{\mathrm{NED}}=$ no evidence of disease; $\mathrm{DOD}=$ dead of disease; $\mathrm{BM}=$ bone marrow; $\mathrm{Fx}=$ fraction; $\mathrm{Bx}=$ biopsy.

chemotherapy. In all patients the diagnosis was obtained by bilateral open-wedge biopsies.

All these children received systemic chemotherapy and local radiation therapy to the testes. Both testes were treated using an anterior portal only. Both testicles were treated because of the high incidence of occult involvement in the clinically normal contralateral testicle. Field sizes were $5 \times 5 \mathrm{~cm}$ to $7 \times 7 \mathrm{~cm}$. Dosages were $1,800 \mathrm{cGy}$ in 1 patient, $2,000 \mathrm{cGy}$ in $4,2,400 \mathrm{cGy}$ in 11 , and $3,000 \mathrm{cGy}$ in 1 patient, delivered in two to three weeks. Cobalt60 was used in 5 patients, orthovoltage $(250 \mathrm{kV})$ in 5 patients, and appropriate electron-beam energy in the remaining 7 patients.

\section{Results}

Seven of the 17 boys are long-term survivors (Table I). Five of them are in complete remis- sion three to six years post-therapy, with an average of 3.4 years. One child is undergoing systemic chemotherapy for bone marrow relapse without evidence of testicular leukemia. In only one of the survivors has post-irradiation testicular relapse developed. He underwent orchiectomy and is alive and well at the time of this writing. The remaining 10 patients died of leukemia or leukemia-related problems. None of them had evidence of testicular involvement at death. Half of them were documented to be free of testicular leukemia at autopsy examination, the rest had clinically benign testes.

Side effects related to radiation therapy were moderate skin erythema and subsequent scrotal cutaneous pigmentation in all boys. In only one child gonadal failure developed and replacement hormonal therapy is being given. This child received radiation therapy by orthovoltage equipment. 


\section{Comment}

Leukemic infiltration of the testes in acute lymphoblastic leukemia is a late complication that is being seen more often due to the dramatic improvements in survival with more effective chemotherapeutic regimens. Extramedullary isolated relapse is most commonly seen in the CNS and in the testes. Several hypotheses have been formulated to explain this occurrence. It has been suggested that the testes may be acting as a sanctuary site similar to the CNS where leukemic cells are protected by some sort of tissue barrier from the systemic chemotherapy. ${ }^{7}$ Another explanation for this leukemic infiltration has been related to the lower temperature of the testes, which could reduce the susceptibility of these cells to cytotoxic drugs. ${ }^{8}$

Radiation therapy has been the treatment of choice for testicular relapse in leukemia and has produced excellent results both with local disease control and long-term survival. ${ }^{9}$ Although leukemic infiltrates are relatively radiosensitive, this appears to vary with the body site. The optimum dose of radiation therapy to the testes has not been established. This is due to the small number of patients with testicular relapse and the variability in treatment modality and total dosage used. There is also a lack of uniform criteria for determining the diagnosis with some series using only clinical findings of testicular enlargement.

D'Angio, Evans, and Mitus ${ }^{10}$ using doses of $1,400 \mathrm{cGy}$ in two weeks obtained good responses when treating leukemic infiltrates. Total doses between 2,000-2,500 cGy are recommended by Atkinson et al. ${ }^{11}$ for patients when a long survival is expected.

Steinfeld $^{12}$ gave $600-900 \mathrm{cGy}$ to 6 patients with control of disease in 4 and failure in 2 . Later he treated the patients who failed with additional $1,400 \mathrm{cGy}$ and 3,500 cGy to achieve local control. Mirro et al. ${ }^{13}$ reported 1 patient had persistent disease after $2,600 \mathrm{cGy}$ in 13 fractions of $200 \mathrm{cGy}$ each. They also found that regression of testicular leukemia is slow after therapy.

Our series, although small, is homogeneous regarding diagnosis, mode of therapy and total dose, all patients receiving treatment at the same institution. Our results regarding local control are highly encouraging. Only in 1 of 17 boys $(6 \%)$ did local failure without any evidence of systemic leukemia develop. The doses given were in a range of 2,000 to $2,400 \mathrm{cGy}$ in most patients, ${ }^{14}$ and minimal complications were encountered. None of the boys treated with modern equipment had endocrine gonadal failure. The only patient in whom gonadal failure developed was a child treated with orthovoltage equipment. At present all patients should receive radiation therapy delivered by megavoltage equipment.

Due to the low incidence of testicular leukcmia, prophylactic irradiation is not recommended. ${ }^{6}$ Orchiectomy should not be considered the primary treatment for testicular leukemia, since radiation is equally effective in achieving local control and is less mutilating without the negative psychologic impact of orchiectomy. ${ }^{15}$ Also, it appears that the risk of gonadal failure from radiation is minimal when adequate doses are used. Endocrine gonadal insufficiency could develop in leukemic patients for a variety of reasons, for example, CNS irradiation, systemic chemotherapy, and direct testicular irradiation. ${ }^{14}$ Results of studies based on basal plasma gonadotropin and testosterone levels have led to the conclusion that prepubertal irradiation of the human testes with doses up to 3,000 rad delivered directly does not produce clear evidence of damage. ${ }^{14}$ This has been recently challenged by Brauner et al. ${ }^{16}$ who found testosterone insufficiency a frequent complication of testicular irradiation. However, its severity appeared to be variable and probably was related to the time elapsed since radiation. Some patients could even maintain a compensated Leydig-cell insufficiency for a long enough period to allow an appropriate progression of virilization.

The importance of careful long-term followup in predicting the course of puberty and determining the need for testosterone replacement therapy is apparent. ${ }^{17}$

In summary, we believe that radiation therapy is the modality of choice for testicular leukemia. Due to the high frequency of bilateral involvement, ${ }^{6}$ bilateral testicular irradiation is required. Occasionally resistance to radiation may occur, and it was seen in 6 per cent of patients in our series. In the absence of systemic disease, reseeding of the testes is unlikely. Megavoltage equipment with either ${ }^{60} \mathrm{Co}$ or preferably with appropriate electron-beam energy should be utilized. Total doses of 2,400 in 12 fractions of $200 \mathrm{cGy}$ appear to be satisfactory, with minimal side effects and excellent local control (94\%). 


\section{Department of Radiation Oncology} Hahnemann University (MS 200)

Broad and Vine Streets

Philadelphia, Pennsylvania 19102

(DR. AMENDOLA)

\section{References}

1. Miller LP, and Miller DR: Acute lymphoblastic leukemia in children: current status, controversies and future perspective, CRC Crit Rev Oncol Hematol 1: 129 (1985).

2. George SL, et al: A reappraisal of the result of stopping therapy in childhood leukemia, N Engl J Med 300: 269 (1979).

3. Miller DR, Nesbit M, Sather H, and Hammond D: Local versus systemic therapy after isolated testicular relapse in childhood acute lymphoblastic leukemia, Proc Am Soc Clin Oncol 1: 132 (C-514) (1982).

4. Hustu HO, and Aur RJA: Extramedullary leukemia, Clin Haematol 7: 313 (1978).

5. Land VJ, et al: Long-term survival in childhood acute leukemia: "late" relapses, Med Pediatr Oncol 7: 14 (1979).

6. Askin FB, et al: Occult testicular leukemia: testicular biopsy at three years continuous complete remission of childhood leukemia, A Southwest Oncology Group Study, Cancer 47: 470 (1981).

7. Kay HEM: Testicular infiltration in acute lymphoblastic leukemia, Br J Haematol 53: 537 (1983).
8. Van Eys J, and Sullivan MP: Testicular leukemia and tem. perature, Lancet 2: 256 (1976).

9. Sullivan MP, et al: Radiotherapy (2500 rad) for testicular leukemia, Cancer 46: 508 (1980).

10. D'Angio GJ, Evans AE, and Mitus A: Roentgen therapy of certain complications of acute leukemia in childhood, AJR 82: 541 (1959).

11. Atkinson K, Thomas PRM, Peckham MJ, and McElwain TJ: Radiosensitivity of the acute leukemic infiltrate, Eur J Cancer 12: 535 (1976).

12. Steinfeld AD: Radiation therapy in the treatment of leukemic infiltrates of the testes, Radiology 120: 681 (1976).

13. Mirro JR, et al: Testicular leukemia relapse: rate of regression and persistent disease after radiation therapy, J Pediatr 99: 439 (1981).

14. Shalet JM, Beardwell CG, Jacols HS, and Pearson D: Testicular function following irradiation of the human prepubertal testis, Clin Endocrinol (Oxf) 9: 483 (1978).

15. Heaney JA, Klauber GT, and Conley GR: Acute leukemia: diagnosis and management of testicular involvement, Urology 21: 573 (1983).

16. Brauner $\mathbf{R}$, et al: Leydig-cell function in children after direct testicular irradiation for acute lymphoblastic leukemia, $\mathrm{N}$ Engl J Med 309: 25 (1983).

17. Pasqualini $\mathrm{T}$, et al: Evaluation of testicular function following long-term treatment for acute lymphoblastic leukemia, Am J Pediatr Heniat Oncol 5: 11 (1983). 